\title{
Identification and specific variety of actinomyces of streptomycetes genus in some chernozems of Ukraine
}

\author{
Oksana Syshchykova - Vitalii Gryshko \\ Plant Physiology and Soils Biology Department, Kryvyi Rig Botanical Garden NAS of Ukraine, 50, Marshaka str., \\ Kryvyi Rig, 50089, Ukraine, e-mail: vit.grishko@rambler.ru
}

Keywords: streptomycetes, microbial cenosis, chernozem usual, chernozem southern, biodiversity

SUMMARY

\begin{abstract}
Is definite the quantitative and quality composition of chernozem usual and southern streptomycetes cenosis. It is rotined that humus horizons of chernozem usual more biogenic, than chernozem southern. Analysis of specific structure of streptomycetes association and calculation of some biodiversity indexes by Margalef, Berger-Parker and Serensen it was allowed to set the specific features of forming of these microorganisms cenosis in investigated soils.
\end{abstract}

\section{INTRODUCTION}

Different subtypes of chernozems differ as on microorganisms quantitative composition, including, streptomycetes, so on microorganisms taxonomical groups correlation in a cenosis (Sherbakov et al., 1983). By researches of Y.Cai (Cai et al., 2004) it is rotined that in chernozems of east part of Cinhai-Tibet tableland (China) an amount of microorganisms of actinomyces line is $1.4 \bullet 10^{7} \mathrm{CFU}$ (colony forming units)/g of soil. The species of Streptomyces genus prevail among them (82\%). Analogical information received by N.A.Manucharova (Manucharova et al., 2004), which it is set that in the actinomyces complex of chernozem usual from Russia dominate the Streptomyces genus, species of which, from data of V.M. Gryshko (Gryshko, 1998), more sensible to the changes of soil-ecological terms. However comparative researches in relation to streptomycetes participating in forming of microbal cenosis of chernozem southern and chernozem usual in a steppe area not conducted.

For description of biotic variety of streptomycetes cenosis and degrees of domination of certain species in chernozem usual and southern is possible the use of the followings quantitative criteria: index of specific riches by Margalef, measures of domination of certain streptomycetes species by Berger-Parker, and also similarity of different associations by the Serensen coefficient (Andreyuk et al., 2001; Evdokimova-Mozgova, 2001). By works of D.G.Zvyagincev (Zvyagincev-Zenova 2001), E.I.Andreyuk (Andreyuk-Valagurova, 1992) and O.V.Syshchykova (Syshchykova, 2006; Syshchykova-Gryshko, 2006), it is rotined that among the streptomycetes in chernozem soils (chernozem usual little humused, chernozem southern heavily loamy) dominated the species from Albus section, also more frequent than all there are species, belongings to the section Cinereus, series Achromogenes, Chromogenes, Violaceus and Aureus, but regardless there is a question of composition and specific variety of streptomycetes association in chernozem soils. Therefore the aim of researches was establishment of differences in quantitative and structural composition of microorganisms of Streptomyces genus association in chernozem usual and southern and description of biotic variety in the streptomycetes cenosis of the indicated soils.

\section{MATERIALS AND METHODS}

The objects of researches it was been chernozem usual low-powered loamy and chernozem southern salinizated middle-powered. Description of vegetation on monitoring areas was conducted on the generally accepted methods of geobotanical researches (Lavrenko-Korchagin, 1972; Mirkin et al., 2001). Description of soil cuts - by I.I.Nazarenko (Nazarenko et al., 2004), F.Ya.Gavrilyuk (Gavrilyuk, 1963) and M.I.Polupan (Polupan et al., 2005).

Area 1. Near beam area of Vlasova beam (Petrovskiy dist., Kirovogradskaya area). Project coverage of vegetable cover is $67 \%$. In a vegetable cover prevails Poa angustifolia L., Elytrigia repens (L.) P.B., Koeleria gracilis Pers., Euforbia seguierana Neck., Stachys transsilvanica Schur, Salvia nemorosa L.

Cut № 1. Chernozem usual low-powered loamy.

$\mathrm{H}_{0}-0-5 \mathrm{~cm}$. Fragmentary surface mortmass.

$\mathrm{H}_{\mathrm{d}}-$ 0-30 cm. Black, fresh, continuous-turfy, grainy-bumpy, size of aggregates 3-5 mm., aggregates waterstable, phyto- and zoogenic nature, loamy, moderato dense. It is marked the cracking and disintegration. Porosity $75-80 \%$ pores of biogenic nature. Passing to horizon of $\mathrm{Hp}$ is gradual, by the structure, closeness and color.

$\mathrm{Hp}_{\mathrm{k}}-30-47 \mathrm{~cm}$. Dense, darkly-grey with a pale yellow tint, bumpy structure with carbonate mould on the surface of structural aggregates, loamy, fresh, chappy, porosity $60 \%$. Size of aggregates 10-12 mm. Stormily boils up from $10 \% \mathrm{HCl}$. 
$\mathrm{hP}_{\mathrm{K}}-47-60 \mathrm{~cm}$. Pale yellow-grey, poorly structured. Molehill is marked. Transition is gradual. Fresh, loamy, porosity $45-50 \%$. A structure is poorly expressed, chappy. Disintegrates. Stormily boils up from $10 \% \mathrm{HCl}$.

$\mathrm{P}_{\mathrm{k}}-60-90 \mathrm{~cm}$. Pale yellow carbonate loess. Autogenic carbonate inclusions from $62 \mathrm{~cm}$.

In elementary soil processes prevails steppe humus accumulation, redistribution of carbonates in a profile with formation of efflorescences.

Area 2. Located near to a burial mound in the district of Svistunova beam (Kryvyi Rig). Project coverage of vegetable cover is 30-40\%. In a vegetable cover prevails Koeleria gracilis Pers and Euphorbia stepposa Zoz.

Cut № 2. Chernozem southern salinizated middle-powered.

$\mathrm{H}_{\mathrm{d}}-0-25 \mathrm{~cm}$. Grainy-bumpy. Subhorizon $0-10 \mathrm{~cm}$ is selected by the diminished closeness and grainy structure. Thickly pierced the roots of herbs, which forming a mattae. Dense, aggregates phyto- and zoogenic. Boils up from $10 \mathrm{HCl} \%$ from a surface, stormily with $60 \mathrm{~cm}$. Is marked the cracking of structure, disintegrates. Porosity $75-80 \%$ pores of biogenic nature. Passing to horizon of $\mathrm{Hp}$ is gradual, by the structure and closeness.

$\mathrm{Hp}_{\mathrm{s}}-25-40 \mathrm{~cm}$. Black, more dense, than previous, prismatic, salinizated. Gradually passes in $\mathrm{hP}$.

$\mathrm{hP}_{\mathrm{k}}-40-60 \mathrm{~cm}$. Bumpy, structure is poorly expressed, aggregates not strong. Passes in $\mathrm{P}$ by flowes.

$\mathrm{Pk}$ - from $60 \mathrm{~cm}$ is the carbonate loess.

Soil samples of chernozerms it was selected in summer by the generally accepted methods on a depth - 0-5; $5-15 ; 15-25 ; 25-35 ; 40-50 ; 50-60 ; 60-70$ and 70-90 cm (Zvyagincev, 1980). For the study of middle amount and quality composition of microflora analysed a middle soil sample, consisting of 5 individual samples, weighing 100-200 g. Researches of microbial cenosis were carried out in all of soil horizons. For microbiological sowing and subsequent selection of streptomycetes were preparing a soils suspension, which were sowing on the hard nourishing medium - starch-ammonium agar. The count of microorganism's colonies was conducted on 7-10 days. The selection of clean culture of streptomycetes was conducted by the bowl-shaped method of exhausting stroke with the subsequent transfer of culture from the isolated colony in a test tube (Egorov, 1995).

Identification of microorganisms of genus Streptomyces was conducted with the use of the methodical pointing of actinomyces determinant G.F.Gauze (Gauze et al., 1983), description of actinomyces species of genus Streptomyces [Valagurova et al., 2003) and computer program of their identification StmId, developed the employees of D.K.Zabolotny Institute of Microbiology and Virology NAS of Ukraine.

Streptomycetes description was conducted on the followings diagnostic criteria: morphological (form of spores chainlets; character of spores shell surface was determined by the scanning electronic microscope JEOL JSM-6060 LA (Japan)); cultural (coloring of air and substrate mycelium by the scale of A.S.Bondarcev (Bondarcev, 1954); presence of soluble and melanoid pigments); physiological (use as a source of growth the different hydrocarbons; biochemical features; common-biological properties) on the determinant of actinomyces of genus Streptomyces (Valagurova et al., 2003).

The analysis of structure of streptomycetes associations was conducted with the use of the criteria generally accepted in ecology. The degree of prevailing of species was calculated by the Berger-Parker index (d):

$$
\mathrm{d}=\frac{\mathrm{Nmax}}{\mathrm{N}}
$$

(Evdokimova - Mozgova, 2001, Megarran, 1992)

where: Nmax is a quantity of the most presented specie, $\mathrm{N}$ is a general amount of individuals. Is generally accepted the use of reversed Berger-Parker index (1/d), so that its increase was showing the growth of diversity and diminishing of prevailing degree of separate species.

For the estimation of specific riches of streptomycetes associations was used the Margalef index (Dmg), depending on the amount of rare species:

$$
\mathrm{Dmg}=\frac{\mathrm{S}-1}{\ln \mathrm{N}}
$$

(Megarran, 1992; Zvyagincev - Zenova, 2001)

where: $\mathrm{S}$ is an amount of the species selected in an association, $\mathrm{N}$ is a general amount of all $\mathrm{S}$ species.

Likeness of streptomycetes associations of different edatopes was estimated by the Serensen coefficient of similarity (Cs):

$$
\mathrm{Cs}=\frac{2 \mathrm{j}}{\mathrm{a}+\mathrm{b}}
$$

(Megarran, 1992; Zvyagincev - Zenova, 2001)

where: $a-$ amount of species of the first association, $b$ - amount of species of the second association, $\mathrm{j}-$ amount of general species of both associations.

The statistical processing of experimental data was conducted by the generally accepted methods of selfreactance statistics at 95\% level of meaningfulness by B.A.Dospekhov (Dospekhov, 1985) and A.A.Egorshin (Egorshin-Lisovoy, 2005). 


\section{RESULTS AND DISCUSSION}

The conducted researches were showing the presence in chernozem soils of features of microorganism's, which assimilates mineral nitrogen, amount fluctuation. So, in horizon of fragmentary surface mortmass $\left(\mathrm{H}_{0}-\right.$ organic-humus horizon) chernozem usual a general amount of microorganisms was 17.9, and streptomycetes 3.6 $\mathrm{mln} / \mathrm{g}$. soils, in humus-cespititious horizon 16.3 and $5.1 \mathrm{mln} / \mathrm{g}$. soils accordingly (table. 1). By a side with this, in chernozem southern salinizated middle-powered horizon of fragmentary surface mortmass absents, and in humus-accumulating horizon the general quantity of microorganisms diminishes on $2 \mathrm{mln} / \mathrm{g}$. soils, while the streptomycetes amount was less than in 1.2 time as compared to chernozem usual, though made $30 \%$ from the general amount of microorganisms.

The decline of microorganism's quantity is set in lower genetic horizons of soil, both in chernozem usual and in southern. In chernozem usual low-powered loamy in transitional humus-accumulating genetic horizon the general amount of microorganisms there is less than in overhead horizons in 2.4 time, while streptomycetes amount - in 1.7 time (Table. 1). Analogical information is received by O.V.Patrusheva and N.V.Veligonova (Patrusheva-Veligonova, 2002), which is set that maximal microorganisms amount in chernozem usual Krasnodarsky edge is concentrated in a layer $0-20 \mathrm{~cm}$ and quickly diminishes on a profile. In chernozem usual in transitional humus-accumulating genetic horizon the general amount of microorganisms in 3 times less than in humus-accumulating, and streptomycetes participating in the cenosis of microorganisms, which utilizing mineral nitrogen makes $29 \%$ from a general amount. The resulted decline of microbial cenosis quantity, probably, is explained the best enriching of superficial layers of soil by an organic matter, necessary for functioning of heterotrophic microbal association.

Table 1.

General amount of microorganisms and streptomycetes (mln/g. soils) in zonal soils

\begin{tabular}{|c|c|c|c|c|c|}
\hline \multicolumn{3}{|c|}{ Chernozem usual low-powered loamy } & \multicolumn{3}{|c|}{ Chernozem southern salinizated middle-powered } \\
\hline Soils layer, $\mathrm{cm}$ & Genetic horizon & $\mathrm{M} \pm \mathrm{m}$ & Soils layer, $\mathrm{cm}$ & Genetic horizon & $\mathrm{M} \pm \mathrm{m}$ \\
\hline \multicolumn{6}{|c|}{ General amount of microorganisms } \\
\hline $0-5$ & $\mathrm{H}_{0}$ & $17.9 \pm 1.13$ & $0-10$ & \multirow{3}{*}{$\mathrm{H}_{\mathrm{d}}$} & $5.9 \pm 0.21$ \\
\hline $5-10$ & \multirow{3}{*}{$\mathrm{H}_{\mathrm{d}}$} & $10.5 \pm 0.66$ & $10-20$ & & $4.2 \pm 0.42$ \\
\hline $10-25$ & & $3.1 \pm 0.55$ & $20-30$ & & $4.2 \pm 0.26$ \\
\hline $25-30$ & & $2.7 \pm 0.21$ & $30-40$ & $\mathrm{Hp}_{\mathrm{s}}$ & $4.8 \pm 0.23$ \\
\hline $30-40$ & \multirow[t]{2}{*}{$\mathrm{Hp}_{\mathrm{k}}$} & $3.7 \pm 0.42$ & $40-50$ & \multirow{2}{*}{$\mathrm{hP}_{\mathrm{k}}$} & $2.7 \pm 0.16$ \\
\hline $40-50$ & & $3.1 \pm 0.24$ & $50-60$ & & $2.9 \pm 0.24$ \\
\hline $50-70$ & $\mathrm{Ph}_{\mathrm{k}}$ & $3.9 \pm 0.43$ & $60-70$ & \multirow{2}{*}{$\mathrm{P}_{\mathrm{k}}$} & $1.6 \pm 0.13$ \\
\hline $70-90$ & $\mathrm{P}_{\mathrm{k}}$ & $3.3 \pm 0.39$ & & & \\
\hline \multicolumn{6}{|c|}{ Amount of streptomycetes } \\
\hline $0-5$ & $\mathrm{H}_{0}$ & $3.6 \pm 0.33$ & $0-10$ & \multirow{3}{*}{$\mathrm{H}_{\mathrm{d}}$} & $1.5 \pm 0.14$ \\
\hline $5-10$ & \multirow{3}{*}{$\mathrm{H}_{\mathrm{d}}$} & $2.8 \pm 0.26$ & $10-20$ & & $1.5 \pm 0.2$ \\
\hline $10-25$ & & $1.2 \pm 0.21$ & $20-30$ & & $1.3 \pm 0.16$ \\
\hline $25-30$ & & $1.1 \pm 0.2$ & $30-40$ & $\mathrm{Hp}_{\mathrm{s}}$ & $1.4 \pm 0.25$ \\
\hline $30-40$ & \multirow[t]{2}{*}{$\mathrm{Hp}_{\mathrm{k}}$} & $1.7 \pm 0.14$ & $40-50$ & \multirow{2}{*}{$\mathrm{hP}_{\mathrm{k}}$} & $0.79 \pm 0.12$ \\
\hline $40-50$ & & $1.3 \pm 0.21$ & $50-60$ & & $0.62 \pm 0.08$ \\
\hline $50-70$ & $\mathrm{Ph}_{\mathrm{k}}$ & $1.5 \pm 0.1$ & $60-70$ & \multirow[t]{2}{*}{$\mathrm{P}_{\mathrm{k}}$} & $0.87 \pm 0.11$ \\
\hline $70-90$ & $\mathrm{P}_{\mathrm{k}}$ & $1.0 \pm 0.07$ & & & \\
\hline
\end{tabular}

At diminishing of humus amount in transitional humus-accumulating genetic horizon (hP) with predominance of maternal breed the general microorganism's quantity was diminished in 4.2 and 1.7 times as compared to two overhead soils horizons accordingly. An analogical tendency is marked and for streptomycetes, amount of which went down in 2-3 times. Analysis of microorganism's quantity in the noted genetic horizon of chernozem southern showed analogical tendency of change of both general amount of microorganisms and streptomycetes (Table. 1).

Figure1. Haracter of surface of streptomycetes spores shell: a - smooth (S. brasiliensis-1), b - uneven (S. nidulosus), c - spiked (S. curacoi), d - with hairsprings (S. grisinus)
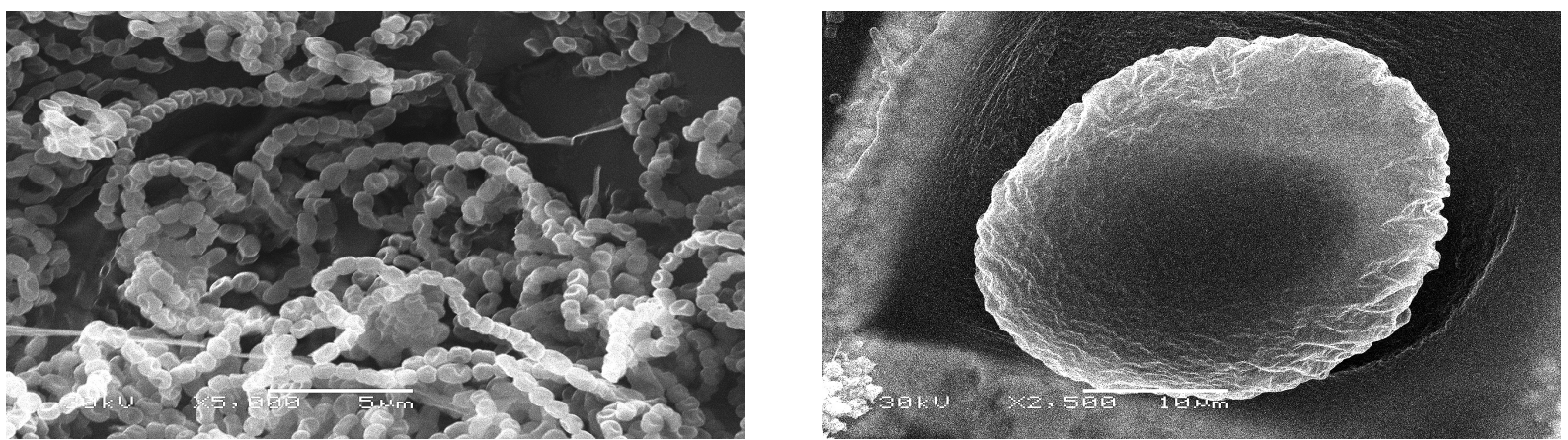

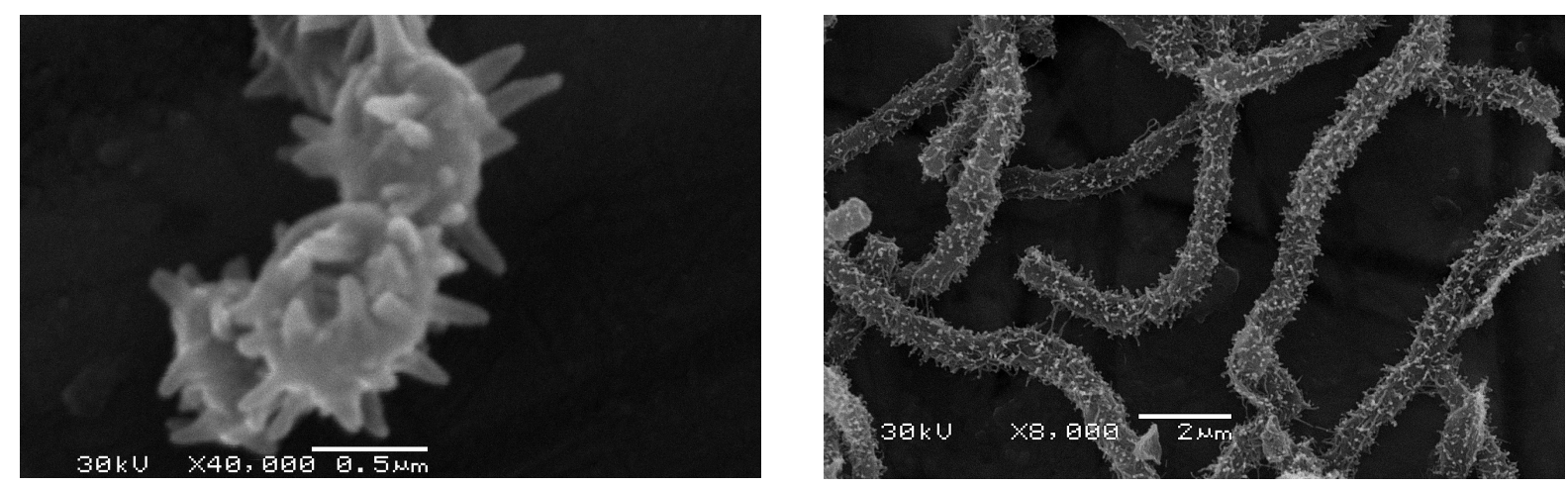

Thus, in chernozem usual low-powered loamy is set the maximal amount of microorganisms, apt at utilization of mineral nitrogen, and streptomycetes prevail among which, that testifies about greater biogenic of this subtype of chernozem than chernozem southern salinizated middle-powered.

For determination of specific composition of streptomycetes cenosis in chernozems was conducted the identification of selected 58 isolates. Identification of the selected cultures was carried out on morphological, cultural and physiological-biochemical properties. Research of spores morphology by a scanning electronic microscope showed, that $63.8 \%$ investigated cultures had a smooth spores surface, $24.1 \%$ - spiked, $8.6 \%$ uneven (Figure 1.). Only for one culture is characteristic the presence of hairsprings on the surface of shell. The most isolates have lines sporiferouses, $17.2 \%$ - spiral, $13.8 \%$ - as imperfect spirals and loops, located monopodial and at separate species they are collected in rings or in unreal rings.

Establishment of streptomycetes cultural properties on the Gauze-1 mineral agar and avenaceous agar showed, that were most widely presented isolates with the white and grey coloring of air mycelium (58\%). For substrate mycelium are characteristic the different tints brown colors. To form soluble and melanoid pigments are capable $39.6 \%$ and $63.7 \%$ isolates accordingly.

Almost all of the selected cultures utilize glucose and saccharose. A few in a less measure isolates utilize ramnose, arabinose, raffinose and fructose, while xylose is not utilized by $38 \%$ cultures. Together with it, it is set that most isolates inherent property to utilize polyols (sorbitol, mannitol, inositol).

The primary streptomycetes amount is able to utilize the nitroorganic compounds, for example peptones and proteins. The amino acid, utilized the cells of microorganisms directly in the processes of biosynthesis or subject breaking up to more simple compounds at breathing and fermentation appear in the process of enzymatic hydrolysis of proteins. The conducted researches allowed to set that the process of amino acid desamination with formation of ammonia is carried out by $64 \%$ studied cultures, and to breaking up of sulfur-containing amino acid, with formation of the sulphuretted hydrogen are capable 57\% isolates (Table. 2).

Some streptomycetes is able to use as final electrons acceptor not oxygen, but nitrates. High activity of nitratreductase, which caused nitrates reduction marked only at 18 cultures, by a side with this less intensity of its functioning is incident to 7 isolates, while other cultures are not able to utilize nitrates as electrons acceptor. Formation of molecular nitrogen is carried out only by 12 cultures from collection.

Tests on streptomycetes ability to synthesize out-cellular enzymes showed that all of the studied cultures showed amylolytic, cellulolytic and proteolytic activity. However intensity of production of these enzymes is different. So, almost all of the studied isolates are able to product an amylase and collagenase, except for cultures № 60, 61 and 63, which not hydrolased starch and № 61, 62 and 65, which do not dilute gelatin.

The study of cellulolytic activity showed that $57 \%$ investigated isolates had very good or good growth on a filtration paper, submerged in a liquid nourishing medium (beef-extract broth) and only 3 cultures destroy it (№ 15, 26 and 59). Other selected isolates did not show this specific enzymatic activity.

Table 2.

Ability of selected streptomycetes cultures to out-cellular enzymes forming

\begin{tabular}{|c|c|c|c|c|c|c|}
\hline \multirow{3}{*}{ № of isolates } & \multirow{3}{*}{ Amylolytic activity } & \multirow{2}{*}{\multicolumn{2}{|c|}{ Cellulolytic activity }} & \multicolumn{3}{|c|}{ Proteolytic activity } \\
\hline & & & & \multirow{2}{*}{ Gelatin dilution } & \multirow{2}{*}{ Casein proteolysis } & \multirow{2}{*}{ Milk coagulation } \\
\hline & & Growth & Destruction & & & \\
\hline 1 & ++ & ++ & - & +++ & - & +++ \\
\hline 2 & +++ & +++ & - & +++ & - & ++ \\
\hline 3 & ++ & ++ & - & +++ & - & +++ \\
\hline 4 & +++ & +++ & - & +++ & - & +++ \\
\hline 6 & +++ & +++ & - & +++ & +++ & ++ \\
\hline 7 & +++ & - & - & +++ & +++ & +++ \\
\hline 8 & + & - & - & +++ & - & ++ \\
\hline 9 & +++ & ++ & - & +++ & - & ++ \\
\hline
\end{tabular}




\begin{tabular}{|c|c|c|c|c|c|c|}
\hline 10 & + & + & - & +++ & ++ & + \\
\hline 11 & +++ & +++ & - & +++ & - & + \\
\hline 12 & +++ & - & - & +++ & + & + \\
\hline 13 & + & +++ & - & +++ & - & - \\
\hline 14 & ++ & - & - & +++ & - & +++ \\
\hline 15 & ++ & + & + & +++ & + & + \\
\hline 16 & +++ & - & - & +++ & - & - \\
\hline 17 & +++ & +++ & - & ++ & ++ & + \\
\hline 18 & ++ & ++ & - & ++ & ++ & + \\
\hline 19 & + & + & - & +++ & - & ++ \\
\hline 20 & +++ & +++ & - & +++ & + & + \\
\hline 21 & +++ & - & - & +++ & + & - \\
\hline 23 & +++ & - & - & +++ & - & +++ \\
\hline 25 & ++ & ++ & - & ++ & ++ & + \\
\hline 26 & ++ & ++ & ++ & +++ & + & - \\
\hline 27 & +++ & +++ & - & +++ & +++ & + \\
\hline 28 & + & - & - & ++ & - & - \\
\hline 29 & +++ & - & - & +++ & +++ & - \\
\hline 30 & + & - & - & ++ & - & + \\
\hline 31 & +++ & - & - & +++ & - & - \\
\hline 33 & + & ++ & - & +++ & - & + \\
\hline 34 & + & - & - & +++ & - & - \\
\hline 35 & +++ & - & - & +++ & +++ & ++ \\
\hline 36 & +++ & - & - & +++ & - & + \\
\hline 37 & ++ & ++ & - & +++ & ++ & - \\
\hline 38 & ++ & - & - & ++ & - & - \\
\hline 40 & ++ & + & - & +++ & - & - \\
\hline 41 & + & + & - & +++ & + & - \\
\hline 43 & +++ & +++ & - & +++ & +++ & - \\
\hline 44 & ++ & +++ & - & ++ & - & ++ \\
\hline 45 & +++ & +++ & - & +++ & - & - \\
\hline 46 & ++ & +++ & - & +++ & + & ++ \\
\hline 47 & +++ & - & - & +++ & - & + \\
\hline 48 & +++ & - & - & +++ & - & + \\
\hline 49 & ++ & + & - & ++ & + & + \\
\hline 50 & ++ & - & - & ++ & - & - \\
\hline 51 & +++ & - & - & ++ & - & + \\
\hline 52 & +++ & +++ & - & + & +++ & + \\
\hline 53 & +++ & ++ & - & ++ & - & - \\
\hline 54 & +++ & ++ & - & ++ & +++ & +++ \\
\hline 55 & +++ & - & - & ++ & - & - \\
\hline 56 & +++ & +++ & - & ++ & +++ & + \\
\hline 58 & +++ & - & - & + & + & + \\
\hline 59 & ++ & + & + & +++ & + & + \\
\hline 60 & - & - & - & + & - & - \\
\hline 61 & - & - & - & - & - & - \\
\hline 62 & ++ & - & - & - & - & + \\
\hline 63 & - & - & - & +++ & + & - \\
\hline 64 & +++ & ++ & - & ++ & + & + \\
\hline 65 & +++ & ++ & - & - & - & - \\
\hline
\end{tabular}

Note: +++ wery good growth or reaction, ++ good growth or reaction, + weak growth or reaction, - absence of growth or reaction

At growth on milk microorganisms, selecting proteolytic enzymes (proteases), which catalyzed breaking up of proteins on peptides, in a few days cause coagulation and peptonisation of milk, that is accompanied dissolution of casein pieces, fall of sediment and brightening of lactoserum. Coagulation of milk and proteolysis of casein is simultaneously carried out by isolates № 6, 7, 35, 52, 54 and 56, and a weak positive reaction is observed at 13 cultures. At $24 \%$ probed cultures is fixed only coagulation (table 2).

Complete absence of proteolytic enzymes is marked only at two cultures № 61 and 65, and at isolates № 60 and 62 is fixed a very weak selection only one from three enzymes in medium. So, at a culture № 60 there was insignificant collagenase activity, and at № 62 weak capacity for coagulation of milk. 
The analysis of the received data, with the use of the computer program of streptomycetes identification StmID, allowed identifying the selected isolates with the percent of coincidence to $95 \%$ with the base cultures of Institute of microbiology and virology NAS of Ukraine.

The conducted identification, of streptomycetes cultures abstracted from chernozem soils, enables to assert that in humus-accumulating horizon of chernozem usual low-powered loamy in a structure of streptomycetes association prevail $S$. violaceomaculatus (section Roseus), a stake of participation of which is $20,5 \%$ and $S$. sporoherbeus (section Azureus) - 18,5\%. For most other selected species the percent of participation does not exceed 3\% and only for two species (S. aerionidulus and S. grisinus) it is 12.4 and $9.3 \%$ accordingly (table 3 ). Together with it, in soil of chernozem southern salinizated middle-powered in the indicated genetic horizon in the streptomycetes cenosis also prevail S. sporoherbeus $-20.1 \%$ and S. grisinus (section Cinereus series Achromogenes) $-18.2 \%$. Together with this, in a cenosis in 7.2 times increases the percent of participation of $S$. enduracidicus (section Cinereus series Chromogenes) and in 2.4 time diminishes the stake of $S$. violaceomaculatus, while the percent of participating in microbial cenosis of all of other streptomycetes species does not exceed 6\% (Table 3).

Stake of participation of species (\%) in the streptomycetes association of zonal soils

\begin{tabular}{|c|c|c|c|c|}
\hline \multirow{2}{*}{ Species } & \multicolumn{4}{|c|}{ Soils horizons } \\
\hline & $\mathrm{H}$ & $\mathrm{Hp}_{\mathrm{s}}, \mathrm{Hp}_{\mathrm{k}}$ & $\mathrm{hP}_{\mathrm{k}}$ & $\mathrm{P}_{\mathrm{k}}$ \\
\hline \multicolumn{5}{|c|}{ Chernozem usual low-powered loamy } \\
\hline S. acidiscabies (A-Ac) & 0.8 & - & - & 6.9 \\
\hline S. aerionidulus $(\mathrm{C}-\mathrm{Ch})$ & 12.4 & 23.2 & 6.5 & 13.8 \\
\hline S. albocrustosus (R-Fu) & 2.3 & 5.3 & - & 6.9 \\
\hline S. brasiliensis-1 (A-Ac) & 1.9 & - & 6.5 & 3.4 \\
\hline S. canadensis $(\mathrm{C}-\mathrm{Ch})$ & - & - & - & 3.4 \\
\hline S. conganensis $(\mathrm{C}-\mathrm{Ach})$ & 2.3 & 2.1 & - & - \\
\hline S. dayalbaghensis (A-Ac) & 7.7 & 13.7 & 16.1 & 20.7 \\
\hline S. ederensis $(\mathrm{C}-\mathrm{Ach})$ & 0.8 & 1.0 & - & - \\
\hline S. enduracidicus $(\mathrm{C}-\mathrm{Ch})$ & 2.7 & - & - & - \\
\hline S. fragmentosporus (A-A) & 2.7 & - & 6.5 & - \\
\hline S. globosus $(\mathrm{C}-\mathrm{Ch})$ & - & 1.0 & - & - \\
\hline S. grisinus (C-Ach) & 9.3 & 10.5 & 32.3 & 20.7 \\
\hline S. hirsutus (C-Ach) & 1.2 & 2.1 & 6.5 & - \\
\hline S. lactogriseus (C-Ach) & 2.3 & 3.2 & - & - \\
\hline S. luteolucescens $(\mathrm{Hf}-\mathrm{H})$ & 0.8 & - & - & 3.4 \\
\hline S. marinolimosus $(\mathrm{R}-\mathrm{F})$ & 1.9 & - & - & - \\
\hline S. nidulosus (C-Ach) & 2.7 & - & - & 6.9 \\
\hline S. ravulus (C-Ach) & 0.4 & - & - & - \\
\hline S. septisporus $(\mathrm{C}-\mathrm{Ch})$ & 2.3 & 3.2 & 3.2 & 3.4 \\
\hline S. spitsbergensis $(\mathrm{R}-\mathrm{Fu})$ & 0.4 & 2.1 & - & - \\
\hline S. sporocaneris $(\mathrm{Hf}-\mathrm{H})$ & 0.4 & - & - & - \\
\hline S. sporoherbeus $(\mathrm{Az}-\mathrm{Co})$ & 18.5 & 8.4 & - & - \\
\hline S. spororutilis (C-Ach) & 1.5 & 2.1 & - & - \\
\hline S. sporostellatus (C-Ach) & 3.1 & 3.2 & - & - \\
\hline S. subhalophilus (A-Ac) & 0.8 & 1.0 & - & - \\
\hline S. violaceomaculatus (R-Ro) & 20.5 & 17.9 & 22.4 & 10.3 \\
\hline \multicolumn{5}{|c|}{ Chernozem southern salinizated middle-powered } \\
\hline S. aerionidulus $(\mathrm{C}-\mathrm{Ch})$ & 3.9 & 2.2 & 6.5 & - \\
\hline S. albocrustosus (R-Fu) & 0.6 & 2.2 & 2.2 & - \\
\hline S. alboflaveolus (Hf-H) & 0.6 & - & - & - \\
\hline S. brasiliensis-1 $(\mathrm{A}-\mathrm{Ac})$ & 1.9 & 2.2 & - & 3.8 \\
\hline S. caelestis (Az-Co) & 1.9 & - & - & - \\
\hline S. canadensis $(\mathrm{C}-\mathrm{Ch})$ & 1.3 & 2.2 & 2.2 & 3.8 \\
\hline S. conganensis (C-Ach) & 1.3 & 4.3 & 2.2 & 3.8 \\
\hline S. dayalbaghensis $(\mathrm{A}-\mathrm{Ac})$ & 5.8 & 10.9 & 8.7 & - \\
\hline S. ederensis (C-Ach) & - & 2.2 & - & - \\
\hline S. enduracidicus (C-Ch) & 19.5 & 23.8 & 10.9 & 7.7 \\
\hline S. fragmentosporus (A-A) & 1.3 & - & 2.2 & 3.8 \\
\hline S. globosus $(\mathrm{C}-\mathrm{Ch})$ & - & - & 10.9 & 19.2 \\
\hline S. grisinus (C-Ach) & 18.2 & 19.6 & 21.6 & 7.7 \\
\hline S. hirsutus (C-Ach) & 0.6 & 2.2 & 2.2 & - \\
\hline S. hofunensis (A-Ac) & 1.3 & - & - & - \\
\hline S. lactogriseus (C-Ach) & 3.9 & 6.5 & 6.5 & - \\
\hline S. ravulus (C-Ach) & - & - & - & 3.8 \\
\hline S. spitsbergensis $(\mathrm{R}-\mathrm{Fu})$ & 2.6 & 2.2 & 4.3 & 3.8 \\
\hline S. sporocaneris $(\mathrm{Hf}-\mathrm{H})$ & 0.6 & - & - & - \\
\hline S. sporoherbeus $(\mathrm{Az}-\mathrm{Co})$ & 20.1 & 8.7 & 6.5 & 15.4 \\
\hline S. spororutilis (C-Ach) & 2.6 & 4.3 & 2.2 & - \\
\hline S. subhalophilus (A-Ac) & 1.3 & 2.2 & 2.2 & - \\
\hline S. tateyamensis $(\mathrm{Hf}-\mathrm{H})$ & 0.6 & - & - & - \\
\hline
\end{tabular}




\begin{tabular}{|l|c|c|c|c|}
\hline S. violaceomaculatus (R-Ro) & 8.4 & 4.3 & 8.7 & 26.9 \\
\hline S. violobrunneus (A-A) & 1.3 & - & - & - \\
\hline
\end{tabular}

Note: brief names of streptomycetes sections and series A - Albus, Ac - Albocoloratus, Az - Azureus, Co - Coerulescens, C - Cinereus, Ch - Chromogenes, Ach - Achromogenes, Fu - Fuscus, Hf - Helvolo-flavus, H - Helvolus, R - Roseus, F - Fradiae, Ro - Roseoviolaceus,

$$
\text { - specie not marked }
$$

In transitional horizons $(\mathrm{Hp}, \mathrm{hP})$ of chernozem usual the stake of participation of $S$. aerionidulus (section Cinereus series Chromogenes) increases on $87 \%$ and in 3.5 time of $S$. grisinus, percent of participation of $S$. violaceomaculatus practically does not change (17.9\%). In chernozem southern dominants there are species which were characteristic and for overhead horizon (Table 3). Substantial differences are acquired the structure of streptomycetes cenosis of chernozem usual and chernozem southern in the lower horizon (P). Dominants in first chernozems subtype are $S$. grisinus and $S$. dayalbaghensis, the stake of participation of which in a cenosis makes more than $20 \%$, while in chernozem southern prevails only $S$. violaceomaculatus.

Works of G.A.Evdokimova and N.P.Mozgova (Evdokimova-Mozgova, 2001) are showing possibility of the Berger-Parker index use for the analysis of specific variety in the streptomycetes association of chernozem soils. The calculation of the indicated index on results our researches testifies about the certain differences in composition of the streptomycetes cenosis in two chernozems subtypes. So, in chernozem usual plenty of species in the streptomycetes cenosis in 1.5 time greater, than in chernozem southern, by a certificate what growth of measure of prevailing of one specie is in an association to 8.3 (Table. 4). The values of Margalef index, as well as in works of E.I.Andreyuk and G.A.Iutinskaya (Andreyuk et al., 2001), showed that chernozems were characterized enough high (4.3 and 4.1) specific riches, as in the streptomycetes association of the indicated soils is identified a maximal (25-26) amount of species. Together with it, table 4 testifies about the high level of similarity of streptomycetes associations of chernozem usual and southern. The calculated Serensen coefficient for the indicated associations is 0.78 .

Table 4.

Margalef (Dmg), Berger-Parker (1/d) indexes and Serensen coefficient (Cs) of streptomycetes association's of zonal soils

\begin{tabular}{|l|c|c|c|}
\hline Variant & Dmg & $1 / \mathrm{d}$ & Cs \\
\hline \hline Chernozem southern & 4.3 & 5.6 & - \\
\hline Chernozem usual & 4.1 & 8.3 & 0.78 \\
\hline
\end{tabular}

Thus, in the streptomycetes association of chernozem usual low-powered loamy is marked greater specific diversity as compared to chernozem southern salinizated middle-powered, although on the values of indexes of specific riches and similarity of streptomycetes association of these soils enough similar.

\section{CONCLUSIONS}

The got results enable to assert that chernozem usual low-powered loamy differs greater biogenic, than chernozem southern salinizated middle-powered. Among dominants in the indicated soils are selected $S$. violaceomaculatus, S. sporoherbeus, S. enduracidicus, S. aerionidulus and S. grisinus. It should be noted that in the streptomycetes association of chernozem usual marked most specific variety; although likeness of streptomycetes cenosis of these soils is enough high.

\section{REFERENCES}

Andreyuk E.I. - Iutinskaya G.A. - Antipchuk A.F. - Valagurova E.V. - Kozyritskaya V.E. - Ponomarenko S.G. (2001): Functioning of soils microbial cenosiss in the conditions of the anthropogenic loading. Oberegy. Kyiv.

Andreyuk E.I. - Valagurova E.V. (1992): Bases of of soil microorganism's ecology. Naukova Dumka, Kyiv.

Bondarcev A.S. (1954): Scale of colors. AS USSR Publ., Moscow, Leningrad.

Cai Y. - Xue Q. - Chen Z. - Chang X. - Sun X. - Si M. - Lai H. - Zhang R. (2004): Relation of soils actinomycetes specific composition with the environment of Cinhai-Tibet tableland east part. Chin J. Appl. Environ. Biol., 10: 3. 378-383.

Dospekhov B.A. (1985): Method of the field experience (with bases of statistical treatment of results of researches). Agropromizdat, Moscow.

Egorov N.S. (1995): Guidance to practical employments on microbiology. MSU Publ., Moscow.

Egorshin A.A. - Lisovoy M.V. (2005): Mathematical planning of the field experiments and experimental data statistical processing. O.N.Sokolovsky Institute of Soil Sciences and Agrochemistry Publ. Kharkiv.

Evdokimova G.A. - Mozgova N.P. (2001): Microorganisms of tundra and forest podsols of Kolsky North. KSC RAS Publ., Apatity.

Gauze G.F. - Preobrazhenskaya T.P. - Sveshnikova M.A. - Terekhova L.P. - Maksimova M.S. (1983): Actinomyces determinant. Genus Streptomyces, Streptoverticillum, Chainia. Nauka, Moscow.

Gavrilyuk F.Ya. (1963): Field research and soils mapping. Visshaya Shkola, Moscow.

Gryshko V.M. (1998): Quantitative composition of some soil microorganisms groups in ecotopes at fluoride contamination. Mikrobiologichny Zhurnal, 60: 2. 13-21.

Lavrenko E.M. - Korchagin A.A. (1972): Field geobotany. Nauka, Leningrad. 
Manucharova N.A. - Belova E.V. - Polyanskaya L.M. - Zenova G.M. (2004): Chitinolytic actinomyces complex of chernozem. Microbiology. 73: 1. 68-72.

Megarran E. (1992): Ecological diversity and its measuring. Mir, Moscow.

15. Mirkin B.M. - Naumova L.G. - Solomesh A.I. (2001): Modern science about plants. Logos, Moscow.

Nazarenko I.I. - Polchina S.M. - Nikorich V.A. (2004): Soil sciences. Books XXI, Chernivtsy.

Patrusheva E.V. - Veligonova N.V. (2002): Proceedings of the 15 Inter-republican Scientific-practical Conference "Actual questions of ecology and nature protection of Russia southern regions ecosystems". Krasnodar.

Polupan M.I. - Solovey V.B. - Velichko V.A. (2005): Ukrainian soils classification. Agrarna Nauka, Kyiv.

Sherbakov A.P. - Mikhnovskaya A.D. - Khaziev F.H. (1983): Biological characteristics of chernozems // In: Russian chernozem 100 years after Dokuchaev. Nauka, Moscow. 89-102.

Syshchykova O.V. (2006): Proceedings of the Int. Scientific Conference "Modern state and perspectives of development of microbiology and biotechnology". Minsk.

Syshchykova O.V. - Gryshko V.M. (2006): Biodiversity of species Streptomyces genus in soils of Kryvyi Rig area. The Bulletin of Kharkiv National Agrarian University. Series Biology, 2: 9. 114-121.

Valagurova E.V. - Kozyritskaya V.E. - Iutinskaya G.A. (2003): Actinomyces of Streptomyces genus, description of species and computer program of their identification. Naukova Dumka, Kyiv.

Zvyagincev D.G. (1980): Methods of soils microbiology and biochemistry. MSU Publ., Moscow.

Zvyagincev D.G. - Zenova G.M. (2001): Actinomyces ecology. GEOS, Moscow. 